\title{
СОВРЕМЕННОЕ СОСТОЯНИЕ ВОПРОСА ИЗУЧЕНИЯ И РАЗВИТИЯ СВЯЗНОЙ РЕЧИ У ДЕТЕЙ ДОШКОЛЬНОГО ВОЗРАСТА С ОБЩИМ НЕДОРАЗВИТИЕМ РЕЧИ
}

\section{THE CURRENT STATE OF THE STUDY AND DEVELOPMENT OF COHERENT SPEECH IN PRESCHOOL CHILDREN WITH GENERAL UNDERDEVELOPMENT OF SPEECH}

\section{E. Balabasova}

G. Vartapetova

Summary: This article deals with the study and development of coherent speech in preschool children with General underdevelopment of speech. To do this, we analyzed the manuals for the diagnosis and formation of coherent speech in preschool children of different authors of the last years of the publication.

Keywords: connected speech, General speech underdevelopment, aborted features of connected speech in General its underdevelopment.
Балабасова Екатерина Николаевна

ФГБОУ ВО «Новосибирский государственный педагогический университет», г. Новосибирск ekaterina.balabasowa@yandex.ru

Вартапетова Галина Михайловна

К.п.н., дочент, ФГБОУ ВО «Новосибирский государственный педагогический университет",

2. Новосибирск vartapetovag@mail.ru

Аннотация: В данной статье рассматривается вопрос изучения и развития связной речи у детей дошкольного возраста с общим недоразвитием речи. Для этого были проанализированы методические пособия по диагностике и формированию связной речи у детей дошкольного возраста разных авторов последних лет издания.

Ключевые слова: связная речь, общее недоразвитие речи, особенности несформированности связной речи при общем ее недоразвитии.

точном уровне фонетико-фонематическую и лексикограмматическую системы языка.

Говоря об особенностях связных высказываний дошкольников с общим недоразвитием речи, ученые отмечают наличие недоразвития различных компонентов языковой системы. Характерными для детских высказываний являются: низкая информативность, нарушения программирования, нарушения грамматической реализации замысла, отсутствие самоконтроля.

Трудности, возникающие у дошкольников при оформлении речи, заключаются в определении логической последовательности событий, в подборе слов, наиболее подходящих для формулирования данного высказывания. Сложным оказывается и самостоятельное изложение текста, и не полное понимание содержания прочитанного.

Трудности, возникающие в процессе овладения навыками связной речи у детей с общим недоразвитием речевой функции, обусловлены недостаточной сформированностью фонетико-фонематической и лексикограмматической систем языка. Дополнительные трудности в овладении связной монологической речью создает наличие у детей вторичных отклонений в развитии ведущих психических процессов (восприятия, внимания, памяти, воображения и др.). В связи с этим важно разо- 
браться, какой именно механизм речевых нарушений срабатывает в каждом отдельном случае и, следовательно, как будет влиять на вариативность проявлений. Это необходимо для разработки адекватных путей и методов коррекции речевых недостатков.

Анализ литературы показал, что данная проблема изучена достаточно широко, но, вместе с тем, необходимо совершенствовать уже имеющиеся приемы и методы, а также осуществлять поиск более эффективных научнообоснованных путей формирования связной речи у детей старшего дошкольного возраста с общим недоразвитием речи.

Исходя из этого, возникает противоречие между обобщенными рекомендациями по формированию связной речи у старших дошкольников с общим недоразвитием речи и особенностями её несформированности при разных клинических формах общего недоразвития речи.

Следовательно, недостаточно разработанным остается вопрос о дифференцированном подходе к формированию связной речи у детей старшего дошкольного возраста с общим недоразвитием речи.

Анализируя специальную литературу последних лет, можно отметить наличие множества различных методик по диагностике и формированию связной речи у детей с общим недоразвитием. При этом мы видим, что нет универсальной диагностической методики, наиболее полно дающей нам информацию о механизме нарушения для выстраивания наиболее эффективного коррекционного воздействия.

Правильно организованное коррекционное обучение и воспитание детей дошкольного возраста требуют всестороннего подробного обследования их речевых и неречевых процессов, определения соотношение дефекта и компенсаторного фона, речевой и коммуникативной активности.

Достаточное число авторов предлагают различные методики обследования связного высказывания (диалогического и монологического), но у каждой из них есть своя специфика.

В методике Т.Б. Филичевой, Г.В. Чиркиной предлагается обратить особое внимание на высказывания детей, возникающие непринужденно, спонтанно, так как при этом раскрываются особенности речи, которые в специально созданных условиях не проявляются [7].

В методике В.П. Глухова для изучения уровня развития связной стороны речи у старших дошкольников С общим недоразвитием речи предлагается использовать различные методы, в том числе и обследование словарного запаса по специальной схеме, так как целенаправленное изучение состояния словаря является необходимой частью комплексного исследования связной речи [3].

О.Е. Грибова в своей методике раскрывает характер помощи детям при обследовании. Стимуляция активности ребенка может заключаться в том, чтобы его все время подгоняли, задавали наводящие вопросы или в организующей помощи [4].

Кроме обследования самостоятельной связной речи ребенка, предлагается обследовать понимание им связной речи на примере рассказов описательного и повествовательного характера. Таким образом, проверяется не столько умение выявлять в тексте логические и временные связи, сколько умение понимать текст в целом.

Одной из авторских программ обследования связной речи дошкольников с ОНР является программа, разработанная В.К. Воробьевой. Как отмечает автор, данная программа отражает специфические особенности связной речи детей с различными вариантами ее недоразвития, помогает понять степень сформированности речевых навыков и механизм нарушения. Материал представлен четырьмя сериями заданий.

Первая серия направлена на выявление репродуктивных возможностей речи дошкольников. При анализе текста используется специальная схема, а уровень связности детских высказываний определяется по предложенной автором шкале.

Вторая серия помогает исследовать продуктивные виды связной речи, а именно выявить умение составлять логическую программу текста и реализовывать ее.

Третья серия заданий включает методы, позволяющие понять особенности поиска, создания, развития и воплощения замысла в связном тексте.

Четвертая серия позволяет выявить уровень ориентировки в признаках связной речи. Дошкольникам предлагается определить, какой из предложенных образцов речи является рассказом, а какой нет. В виде образца выступают: набор слов, отдельных предложений или деформированный текст.

Анализируя результаты всех серий выполненных заданий, предполагается выявление несформированности операций, ведущих к нарушению смысловой цельности и связности речевого сообщения.

На данном этапе своего развития логопедия располагает большим количеством материалов по изучению 
состояния уровня развития связной речи у старших дошкольников с общим недоразвитием речи, но, несмотря на это, представленные и существующие методики по обследованию могут в дальнейшем совершенствоваться, дополняться и тем самым служить основой для создания новых.

В общем комплексе коррекционного воздействия первостепенное значение имеет формирование связной речи. Особенно это необходимо для детей старшего дошкольного возраста, имеющим общее недоразвитие речи, так как высокий уровень развития речи является важным условием успешной учебы в дальнейшем.

Для формирования связного высказывания нужного уровня различные авторы предлагают разнообразные методики. Рассмотрим их более подробно.

Л.Н. Ефименкова в своей методике систематизирует приемы работы по развитию речи детей с общим недоразвитием речи [5].

Коррекционную работу автор делит на 3 этапа. Каждый этап включает в себя задания по формированию и расширению словаря, фразовой речи и выхода в связную речь. Предлагается так же обучать детей с общим недоразвитием речи сначала подробному, затем выборочному и после творческому пересказу, заранее проанализировав текст. Работа над связной речью завершается обучением составлению рассказа из личного опыта.

В своей методике В.П. Глухов предлагает систему обучения рассказыванию детей в несколько этапов с помощью следующих форм: составление высказываний по наглядному восприятию, пересказ прослушанного текста, составление рассказа-описания, рассказывание с элементами творчества [2].

Методика разделяется по периодам и видам обучения (обучение рассказыванию по картинкам, обучения рассказу - описанию предметов, обучение рассказыванию с элементами творчества).

В первом периоде ведется работа по развитию сенсорного восприятия, по формированию навыков элементарного анализа предмета, непосредственно воспринимаемого ребенком, а также детям предлагается формулировать ответы на вопросы взрослого с помощью фраз. Далее проводится работа по формированию навыков составления описания предметов по вопросам, по плану, с опорой на образец, а также формированию умения планировать небольшой описательный рассказ.

Во втором дети учатся описанию предмета по памяти, по собственному рисунку, включению описаний в игровые ситуации.
В методике для каждого вида обучения предлагается примерный речевой материал, методические рекомендации к занятиям, методические требования к обучению, а также представлены варианты примерных планов занятий по формированию связной речи у детей старшего дошкольного возраста с общим недоразвитием речи.

Т.А. Ткаченко предлагает тематическую последовательность занятий несколько отличную от той, что описана в специальной литературе. Она также указывает на то, что дети с общим недоразвитием речи нуждаются во вспомогательных средствах, облегчающих и направляющих процесс формирования связной речи. Это может быть наглядность или моделирование плана высказывания. Упражнения располагаются в порядке от простого к сложному, с постепенным убыванием наглядности и «свертыванием» плана высказывания [6].

Для составления описательных рассказов автор предлагает использовать схемы и наиболее типичные группы предметов (игрушки, одежда и др.), которые дадут ребенку возможность без особых усилий научиться описывать предмет наиболее подробно и в определенной последовательности.

Вопросами развития связной речи, включающей элементы творчества (придумывание сказок, рассказов), стали заниматься такие исследователи как Г.Р. Шашкина, Л.П. Зернова, И.А. Зимина. Они предлагают начинать обучение рассказыванию с элементами творчества сразу после того, как у дошкольников сформировались навыки построения различных типов предложений [8].

В процессе формирования описательной речи у детей с III уровнем общего речевого развития уже на первых этапах обучения рассказыванию по серии сюжетных картинок детям рекомендуется решать некоторые творческие задачи. Так ребенку предлагается восстановить рассказ по отработанной на предыдущем занятии серии без предъявления одной - двух картинок, построить рассказ от первого лица и другое.

Более сложным видом инсценировки серии картинок может служить пантомима. Для формирования внутренней речи детей, которая программирует связное высказывание и сокращает развернутое высказывание до свернутой смысловой схемы, целесообразно в качестве заключительного этапа работы над каждой серией последовательных сюжетных картинок предлагать детям выделять главную мысль в рассказе. Такая работа подводит детей к умению пересказывать услышанные тексты. В своей работе авторы предлагают вводить метод придумывания сказки по предложенному сюжету. Используя усвоенное, они, проявляя творческие способности, вносят элементы нового. 
В методике В.К. Воробьевой описывается работа по формированию у детей дошкольного и младшего школьного возраста монологической речи [1]. Данная методика позволяет успешно усваивать школьную программу, а также учить детей пользоваться монологической речью.

Отличием данной авторской работы, от того, что существует на данный момент, является то, что она учит детей определенным правилам построения связного речевого высказывания.

Методика состоит из четырех разделов. Один из которых направлен на формирование ориентировочных действий, которые в свою очередь позволяют «узнавать» связные сообщения. Следующий раздел дает возможность разобраться в правилах смыслового и языкового построения связного высказывания. Третий помогает закрепить данные правила.
Последний же раздел помогает перейти от правил к самостоятельной связной речи и применяется в работе с младшими школьниками.

Возможность широкого применения данной авторской методики обусловлена тем, что связная речь - это и самостоятельная форма речевого общения, и средство обучения, и средство осуществления контроля за знаниями.

Подводя итог можно сделать вывод о том, что логопедия располагает сейчас достаточным количеством материалов по изучению состояния уровня развития и формированию связной речи у старших дошкольников с общим недоразвитием речи. Данные исследовательские работы имеют обобщенный характер, поэтому каждую из них следует интерпретировать под индивидуальные особенности каждого ребенка.

\section{ЛИТЕРАТУРА}

1. Воробьева В.К. Методика развития связной речи у детей с системным недоразвитием речи /В.К. Воробьева. - М.: АСТ: Астрель: Транзиткнига, 2006. $158 \mathrm{c}$.

2. Глухов В.П. Формирование связной речи у детей дошкольного возраста с ОНР. - М.: АРКТИ, 2004. - 168 с.

3. Глухов В.П., Смирнова М.Н. Исследование особенностей связной речи старших дошкольников с задержкой психологического развития и общим недоразвитием речи //Логопедия. - 2005. - № 3. - c.13-24.

4. Грибова 0.Е. Технология организации логопедического обследования. - М.: АРКТИ, 2017. - 80 с.

5. Ефименкова Л.Н. Формирование речи у дошкольников. - М.: Национальный книжный центр, 2015. - $176 \mathrm{c}$.

6. Ткаченко Т.А. Учим говорить правильно. Система коррекции общего недоразвития речи у детей 6 лет. Пособие для воспитателей, логопедов и родителей. - М.: «Издательство ГНОМ и Д», 2003. - 112 с.

7. Филичева Т.Б. Устранение общего недоразвития речи у детей дошкольного возраста: практ. пособие /Т.Б. Филичева, Г.В. Чиркина. - М.: Айрис-пресс, 2008. -224 c.

8. Шашкина Г.Р. Логопедическая работа с дошкольниками: учеб. пособие для студ. высш. пед. учеб. заведений /Г.Р. Шашкина, Л.П. Зернова, И.А. Зимина М.: Издательский центр «Академия», 2003. - 240 с. 